\title{
Pierre RAINVILLE, La répression de l'art et l'art de la
} répression

Québec, Presses de l'Université Laval, 2019

Philippe Ségur

\section{OpenEdition}

\section{Journals}

Édition électronique

URL : https://journals.openedition.org/rdr/1301

DOI : $10.4000 /$ rdr.1301

ISSN : 2534-7462

Éditeur

Presses universitaires de Strasbourg

Édition imprimée

Date de publication : 16 novembre 2020

Pagination : 205-206

ISBN : 979-10-344-0073-7

ISSN : 2493-8637

\section{Référence électronique}

Philippe Ségur, «Pierre RAINvILLE, La répression de l'art et l'art de la répression », Revue du droit des religions [En ligne], 10 | 2020, mis en ligne le 16 novembre 2020, consulté le 02 mai 2022. URL : http:// journals.openedition.org/rdr/1301 ; DOI : https://doi.org/10.4000/rdr.1301

Ce document a été généré automatiquement le 2 mai 2022.

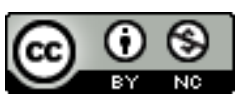

La revue du droit des religions est mise à disposition selon les termes de la Creative Commons Attribution - Pas d'Utilisation Commerciale 4.0 International - CC BY-NC 4.0. 


\title{
Pierre RAINVILLE, La répression de l'art et l'art de la répression
}

Québec, Presses de l'Université Laval, 2019

\author{
Philippe Ségur
}

\section{RÉFÉRENCE}

Pierre RAINVILLE, La répression de l'art et l'art de la répression, Québec, Presses de l'Université Laval, 2019 (Dikè), 116 p.

1 Dans ce livre aussi riche qu'argumenté, l'auteur, professeur de droit pénal à l'Université Laval, s'attache à analyser l'intersectionnalité de la liberté d'expression et de la liberté de religion au carrefour des œuvres d'art - essentiellement écrites et théâtrales - et ce, dans une perspective comparatiste droit canadien/droit européen. Dans la common law, le crime de blasphème oral (blasphemy) et de blasphème écrit (blasphemous libel), conçu à l'origine pour protéger la religion chrétienne de toute critique, avait été, dès le milieu $\mathrm{du} \mathrm{XIX}^{\mathrm{e}}$ siècle, restreint par le juge aux seules attaques excessives. Reprenant cette jurisprudence anglaise, l'article 296(3) du Code criminel canadien ne conserve plus, en 1892, que le libelle blasphématoire visant les seuls écrits. L'infraction est alors constituée par un élément matériel (un excès formel tel que l'offense et le ridicule, ceci incluant la sexualité associée aux manifestations de mépris envers la religion) et un élément subjectif (la volonté de faire offense au sentiment religieux d'autrui). Cette exigence $d u$ caractère intentionnel, qui était inexistante dans la conception initiale $d u$ blasphème, est déterminante : elle a permis le passage « de la protection d'une foi à la protection des sentiments des croyants»(p.24). L'auteur démontre avec conviction combien cette disposition pénale créait une rupture d'égalité entre les citoyens canadiens sur le fondement d'une double discrimination: discrimination de la parole des non-croyants, discrimination des autres religions au profit de la religion chrétienne. 
C'est seulement avec le Criminal Justice and Immigration Act, adopté par le Parlement de Westminster en 2008 et avec la loi canadienne modifiant le Code criminel en 2018 que le crime de libelle blasphématoire a disparu du droit positif. En Europe continentale, il faut attendre 2014 aux Pays-Bas, 2015 en Norvège, 2018 en Irlande et 2017 pour les départements du Haut-Rhin, du Bas-Rhin et de la Moselle en France. Cependant, Pierre Rainville relève partout la réapparition de la prohibition du blasphème sous de nouvelles qualifications telles que la diffamation des religions ou le dénigrement des religions. Ainsi assisterions-nous à «la reconversion de l'interdit du propos blasphématoire sous le couvert de la prohibition de la discrimination envers les adeptes d'une religion ou encore la protection de leurs croyances » (p. 9).

3 En se fondant sur la jurisprudence, l'auteur repère les contours de cette nouvelle prohibition qui «glisse imperceptiblement de l'affront à la religion à l'affront aux croyants » (p. 47). Se refusant à arbitrer la moralité publique, le juge canadien n'évalue les propos blasphématoires à connotation sexuelle qu'en fonction d'un risque de préjudice important et grave, c'est-à-dire incompatible avec le bon fonctionnement de la société. Quant à l'indécence, elle ne saurait être prise en compte dans la mesure où elle ne porte pas atteinte aux valeurs de l'ensemble de la société, sauf hypothèse de représentations sexuelles dégradantes auxquelles le public ne pourrait se soustraire.

4 C'est alors sous l'angle de la protection des identités religieuses contre l'incitation à la haine que les limites au blasphème seront le plus clairement posées. Selon l'arrêt Whatcott de la Cour suprême du Canada en 2013, le propos offensant et, par voie de conséquence, la susceptibilité heurtée des croyants ne suffisent pas à eux seuls à caractériser cette provocation à la haine. Encore faut-il que l'attaque soit extrême et de nature à produire un impact social notable par l'ostracisme de la communauté visée. Dans des analyses éclairantes, Pierre Rainville souligne ici le caractère exonérateur de l'humour aux yeux des juges. De la satire à l'ironie, "le rire même désobligeant ou déplacé n'atteint que très rarement la virulence voulue » (p.69) sans pour autant être un facteur d'impunité totale. Poussée à l'extrême, la dérision peut devenir ferment de haine.

5 S'agissant des droits français et européens, le hiatus - assez frappant à quelques pages d'intervalle - entre l'innocuité déclarée par le juge français d'un dessin du Monde montrant le pape sodomisant un enfant de chœur (CA Paris, 7 juill. 2015, AGRIF c. Fottorino et al.) et la condamnation européenne d'un propos tenu dans un séminaire de formation qualifiant de pédophile le mariage consommé du prophète Mahomet avec une fillette (CourEDH, 25 oct. 2018, E. S. c. Austria) ne fait pas l'objet d'une analyse spécifique qui serait pourtant utile en termes comparatistes et en sociologie du droit. C'est, en effet, la prégnance de la conception française de la laïcité qui garantit la liberté d'expression même si celle-ci offense, contrairement au monde anglo-saxon et à d'autres pays européens où la laïcité ne constitue pas un marqueur culturel et juridique aussi net.

6 Par ailleurs, si « des remarques désobligeantes ou insultantes peuvent, à terme, par leur caractère insidieux et leur perfidie légèrement voilée, faire progresser la mise en vulnérabilité des groupes minoritaires » (p. 75), il serait intéressant d'interroger aussi la situation actuelle des catholiques pratiquants devant l'appréciation judiciaire des propos discriminants à leur endroit, puisqu'ils ne représentent plus que $6 \%$ de la population française (V. J. Fourquet, L'archipel français, Seuil, 2019) et constituent de ce fait un groupe désormais minoritaire. Sur ce point, le lecteur en conclura peut-être de 
lui-même que les catholiques d'aujourd'hui paient d'un prix élevé la suprématie de l'Église catholique d'hier.

\section{AUTEURS}

\section{PHILIPPE SÉGUR}

Professeur de droit public, Université de Perpignan Via Domitia, Centre du droit économique et du développement (CDED) 